\title{
Probing solute distribution and acid-base behaviour in water-in-oil microemulsions by fluorescence techniques ${ }^{\text {is }}$
}

\author{
Maria da Graça Miguel *,1, Hugh D. Burrows, M. Alice Escaroupa Pereira, \\ A. Paula Varela \\ Departamento de Química, Universidade de Coimbra, 3049 Coimbra, Portugal
}

\begin{abstract}
The distribution and acid-base behaviour of the four solutes harmine, chromotropic acid (4,5-dihydroxynaphthalene-2,7-disulfonate, disodium salt), 2-naphthol and 5,10,15,20-tetrakis [4-trimethylammonium)phenyl]-21 $\mathrm{H,23H}$ porphine tetra- $p$-tosylate (TTMP) have been studied in water-in-oil (w/o) microemulsions using fluorescence and absorption spectroscopy. Carbon tetrachloride is a quencher of fluorescence of these compounds, and studies using this as oil phase in microemulsions show that chromotropic acid is located in the water domain, TTMP at the surfactant-water interface, while the distribution of harmine or 2-naphthol depends on the degree of protonation. Detailed studies have been made on harmine. In water/AOT/cyclohexane microemulsions the cationic form is observed up to much higher apparent $\mathrm{pH}$ than in aqueous solutions. An important factor is shown to be the compartmentalisation of hydroxide ions between water pools. Similar effects are observed with the other probes, and it is suggested that compartmentalisation of hydrogen or hydroxide ions is a major effect in many acid-base reactions in microemulsions. The validity of the concept of $\mathrm{pH}$ in microemulsions under these conditions is questioned. Fluorescence lifetime measurements are also shown to provide information on the dynamics of the processes, and demonstrate the importance of diffusion of solutes from organic solvent to the microemulsion pool. A comparison is made of the behaviour of harmine in water/AOT/cyclohexane and water/lecithin/cyclohexane microemulsions. (C) 2001 Elsevier Science B.V. All rights reserved.
\end{abstract}

Keywords: Water AOT cyclohexane; Carbon tetrachloride; Harmine; Microemulsion

\footnotetext{
Invited lecture by MGM at the 12th International Symposium on Surfactants in Solution, Stockholm, 7-11 June 1998.

* Corresponding author. Fax: + 351-39-827703.

E-mail address: mgmiguel@gemini.ci.uc.pt (M. da Graça Miguel).

${ }^{1}$ Also visiting professor at the Physical Chemistry 1, Chemical Center, Lund University, PO Box 124, 22100 Lund, Sweden.
}

\section{Introduction}

Water-in-oil (w/o) microemulsions are thermodynamically stable systems consisting of nanometer sized individual domains of water (sometimes called water pools or droplets), which are separated by a monolayer of amphiphile from an oil continuous region. Their properties have been extensively reviewed [1-7]. One particularly im- 
portant property is the possibility of varying the size of the water pool over a wide range by changing the water/amphiphile mole ratio $\left(\omega_{0}\right)$. Microemulsions find uses in areas as diverse as microreactors for chemical or enzymatic catalysis [4,8-10], matrices for the formation of nanoparticles or monodisperse polymers [11,12] and model systems for biological membranes [4]. For many of these applications, knowledge of the microscopic distribution of solutes is important.

Various techniques have been applied to the study of solute distribution, including NMR spectroscopy, small angle X-ray and neutron scattering, fluorescence and various other photophysical methods [4,6]. In general, with small solute molecules three distinct solubilisation sites can been considered, the water pool, the bulk organic liquid, and the interface. If large, or highly charged, solutes are present, they may also change the microstructure of aggregates or even induce formation of small aggregates around the solute [4]. In cases where acid-base reactions of solute may occur, the dominant site for the solute and its conjugate acid or base may be different. However, it is found, in general, that microemulsions appear to exert a 'buffering' effect, and that the apparent $\mathrm{pH}$ inside a water droplet is different from that of the solution added $[13,14]$. Various methods have been used to try to assess the acidity of the microemulsion water droplets [15-19]. Potentiometric measurements on buffered solutions in water/AOT (sodium(bis-(2-ethylhexyl)sulfosuccinate)/heptane solutions at high $\omega_{0}$ values have shown similar electrical response to that shown by the pure aqueous solutions [15]. However, such measurements are not possible at low $\omega_{0}$ values, and the lack of understanding of the effect of interfacial interactions between the electrodes and microemulsion on observed potentials makes interpretation of these observations highly speculative. An alternative approach has been to measure acid-base equilibria of suitable indicators spectrophotometrically, and to calculate local $\mathrm{pH}$, assuming the applicability of the HendersonHasselbach equation [15-17]. However, this method has been criticised [4], since micellar water has different properties from bulk water, and the $\mathrm{p} K$ of the indicator in such media cannot be measured independently. Another technique that has been used in the case of phosphate buffers to obtain an empirical acidity scale is based on the differences between values of the ${ }^{31} \mathrm{P}$ NMR chemical shift in pure water and microemulsions, assuming that the $\mathrm{p} K$ value of the phosphate is the same in both the systems $[16,18]$. Support for such an approach in the case of phosphate buffers in water/lecithin/deuterobenzene microemulsions is given by the observation of a single ${ }^{31} \mathrm{P}$ NMR signal [20]. However, this method is only applicable where an appropriate buffer, such as phosphate, is present at a sufficiently high concentration such that a uniform distribution is observed in all the droplets. An additional approach has been to determine the water acidity kinetically in terms of proton transfer reactions of certain fluorescent probes [19]. This method is attractive, although it requires both suitable probes, whose properties may be different from other solutes of interest, and information on their localisation sites.

In this paper we will address some points concerning acid-base behaviour of solutes in microemulsions. In particular we will consider three questions:

How do we or can we define $\mathrm{pH}$ in microemulsions?

How important is compartmentalisation of $\mathrm{H}+$ or $\mathrm{OH}$-ions in the acid-base behaviour of solutes in microemulsions?

How is the diffusion or distribution of the probe affected by the $\omega_{0}$ value of the microemulsion?

For this, we will study the acid-base equilibria of a number of fluorescent probes. Particular emphasis will be given to a group of compounds, the $\beta$-carbolines. We have been interested in the photophysical behaviour of these compounds [21-23]. Both synthetic and naturally occurring $\beta$-carboline derivatives are known, and they show photosensitizing activity towards a variety of systems, including bacteria, fungi, viruses, etc [22]. In addition, they are fluorescent products of tryptophan produced in human lenses [24], and may act as markers of metabolic changes. However, for such applications, it is important to know their localisation in biological media. To obtain a deeper understanding on their distribution in such systems, a study has been undertaken of their photophysical behaviour in water/AOT/cyclohex- 
ane microemulsions [22]. In aqueous media, the $\beta$-carbolines undergo complex acid-base equilibria in both ground and excited states to produce cationic, neutral and (in the lowest excited singlet state) zwitterionic forms [21-23]. Structures and equilibria are shown in Fig. 1. In contrast, in nonprotic organic solvents only the neutral form is observed. The ground and excited state $\mathrm{p} K_{\mathrm{a}}$ values are different [25], thus providing a further valuable tool for probing distribution and acidbase behaviour in micro-heterogeneous systems. In water/AOT/cyclohexane microemulsions, it was found [22], that the three compounds norharmane, harmane and harmine appear to be located predominantly at the surfactant/water interface, but that on decreasing $\mathrm{pH}$ there is an increase in partitioning towards the water domain. In dynamic fluorescence studies, four kinetically distinguishable species are observed in the excited state, neutral species in cyclohexane, neutral species in droplets, cation and zwitterion. More detailed studies were made on harmine [22], and these will be described in Section 3.

Water-in-oil (w/o) microemulsions can also be formed using carbon tetrachloride as the organic solvent [26-30], This has an advantage for photophysical studies as it is a good excited state quencher [31], and if luminescence methods are<smiles>[R2]c1cccc2c1[nH]c1ccncc12</smiles>

$\begin{array}{lllll}\text { (1)HARMINE } & \mathrm{R}_{1}=\mathrm{CH}_{3} & \mathrm{R}_{2}=\mathrm{OCH}_{3} & \mathrm{pK}_{\mathrm{a}}=8.0 & \mathrm{pK}_{\mathrm{a}}\left(\mathrm{S}_{1}\right)=12.9 \\ \text { (2)HARMANE } & \mathrm{R}_{1}=\mathrm{CH}_{3} & \mathrm{R}_{2}=\mathrm{H} & \mathrm{pK}_{\mathrm{a}}=7.7 & \mathrm{pK}_{\mathrm{a}}\left(\mathrm{S}_{1}\right)=12.8 \\ \text { (3)NORHARMANE } & \mathrm{R}_{1}=\mathrm{H} & \mathrm{R}_{2}=\mathrm{H} & \mathrm{pK}_{\mathrm{a}}=7.2 & \mathrm{pK}_{\mathrm{a}}\left(\mathrm{S}_{1}\right)=13.0\end{array}$
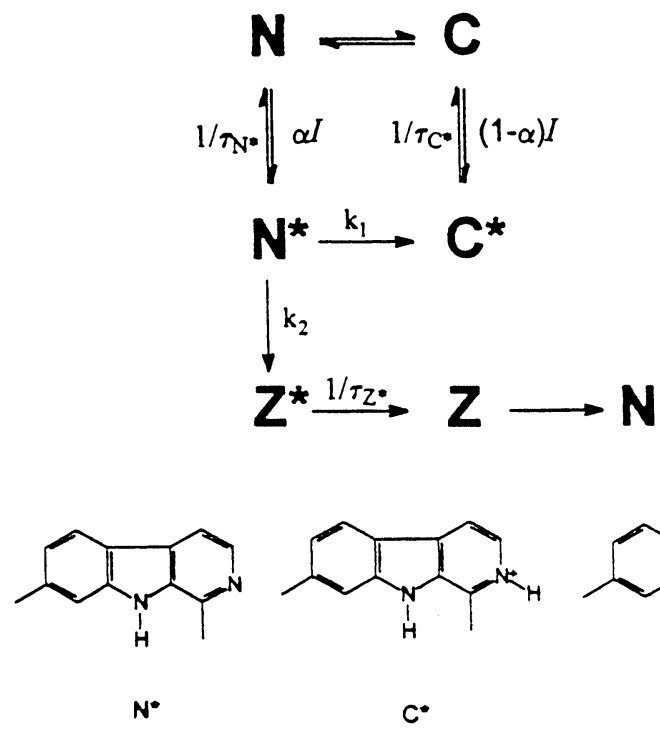

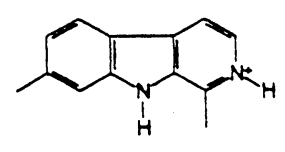

c*

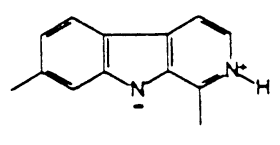

Z

Fig. 1. Structures and acid-base equilibria of $\beta$-carbolines. 
a<smiles>C=C[SH](=O)([O-])c1cc(O)c2c([O-])cc(S(=O)(=O)[O-])cc2c1</smiles>

b<smiles>C=C=C</smiles><smiles>[O-]c1ccc2ccccc2c1</smiles>

c
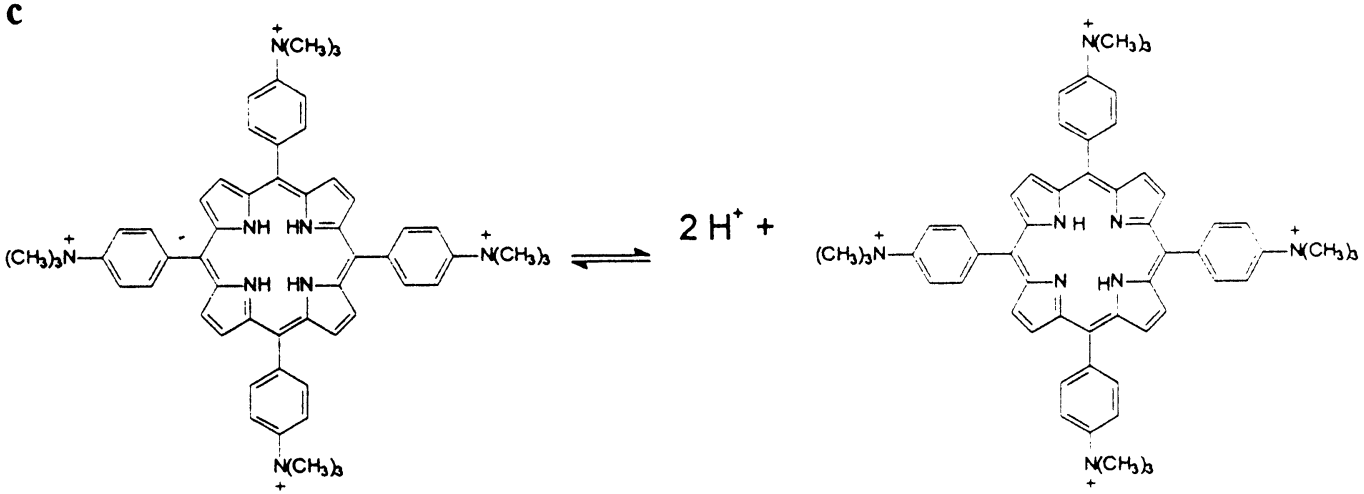

Fig. 2. Structures and acid-base equilibria of (a) chromotropic acid; (b) 2-naphthol; (c) TTMP.

used any fluorescence must arise from solute either in the aqueous domain or the interface.

We have also been interested in w/o microemulsions using lecithin as amphiphile. These have been studied by a variety of spectroscopic and scattering techniques [32-34], and may act as good models for biological cells. In addition, under certain conditions, lecithin forms highly viscoelastic 'microemulsion gels' [35].

In this paper, we will compare the behaviour of harmine in water/AOT/cyclohexane, water/ lecithin/cyclohexane and water $/ \mathrm{AOT} / \mathrm{CCl}^{4} \mathrm{mi}-$ croemulsions. In addition, we will also report the results of a fluorescence study of the distribution and acid-base behaviour in w/o microemulsions of three other probes, 2-naphthol, chromotropic acid and the cationic porphyrin TTMP $(5,10,15,20$-tetrakis[4 - (trimethylammonium)phenyl] - $21 \mathrm{H,23H}$ porphine tetra- $p$-tosylate salt). These three compounds (Fig. 2) were chosen, as they are likely to have dominant distribution in organic phase, aqueous domain and interface, respectively.

\section{Experimental}

The surfactant AOT was purified as described earlier [22]. Chromotropic acid was recrystallised from ethanol-water. 2-Naphthol was recrystallised from hot water after treatment with decolourising charcoal [36]. The lecithin used in this study was a gift from Dr A. Khan, and is from 
the same batch as used in [32]. Carbon tetrachloride was purified by washing with $0.1 \%$ solution of $\mathrm{KOH}$ in ethanol, the ethanol removed by standing over alumina, the solution dried over anhydrous calcium chloride, and finally fractionally distilled from anhydrous potassium carbonate. Millipore or bidistilled water was used in the preparation of microemulsions. Other reagents were of the purest grade commercially available and were used as purchased.

$\mathrm{UV} /$ visible absorption and fluorescence spectra were measured on Shimadzu UV-2100 spectrophotometer and SPEX Fluorolog 111 spec-
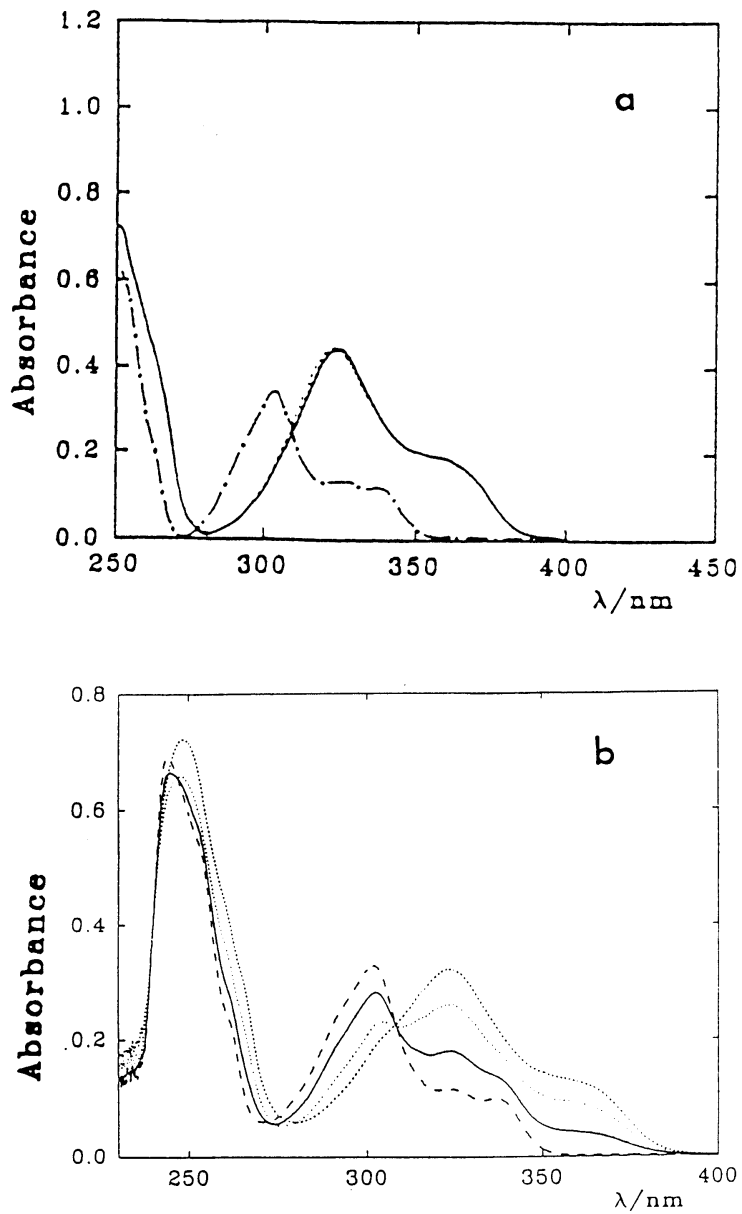

Fig. 3. Absorption spectra of harmine in water/AOT/cyclohexane microemulsions: (a) $\omega_{0}=5$ at $\mathrm{pH} 6.4(-), 12.4(--)$ and 12.8 (-.-); (b) $\omega_{0}=12.5$ at $\mathrm{pH}$ values 5.5 and 12.4. For details see [22]. trofluorimeters respectively. Further details of the apparatus and methods are given in [22]. Fluorescence decays were obtained using time-correlated single photon counting, as described previously [21-23,37].

\section{Results}

\subsection{Harmine}

$\mathrm{UV} /$ visible absorption spectra were run of solutions of harmine in water/AOT $(0.1 \mathrm{M}) /$ cyclohexane microemulsions at $\omega_{0}=5$ and various $\mathrm{pH}$ values (Fig. 3; note, the $\mathrm{pH}$ value is of the unbuffered aqueous solutions added). Between $\mathrm{pH}$ 6.8 and 12.4 only, the absorption spectrum of the cationic form is observed, while above $\mathrm{pH} 12.8$, the characteristic absorption of the neutral form is also seen. The $\mathrm{p} K_{\mathrm{a}}$ of harmine in water is 8.0 , so that dissociation of the harmine cation is occurring at much higher apparent $\mathrm{pH}$ than in aqueous solution. Similar spectral changes are observed in the fluorescence spectra (Fig. 4), but the decrease in cation emission and increase in neutral form emission occurs at slightly lower apparent $\mathrm{pH}$ (10.3-12.0). In contrast to what is observed in aqueous solution [23], no significant emission is observed from the zwitterion, suggesting that harmine is either predominantly at the interface, or may partition to the bulk organic solvent. Partitioning studies between octanol and water [22] and solubility measurements [38] show that the neutral form only has a low solubility in the aqueous phase. The behaviour of harmine in these microemulsions has also been studied at various $\omega_{0}$ values [22]. Representative absorption and emission spectra at $\omega_{0}=12.5$ are shown in Figs. 3 and 4, and good isosbestic points are observed. At this $\omega_{0}$ value a weak zwitterion emission is also observed. Fluorescence lifetimes also give information on acid-base behaviour and distribution, and decays have been studied for $\omega_{0}=12.5$ looking at emissions at 350, 410 and $500 \mathrm{~nm}$, wavelengths corresponding predominantly to emission from excited neutral, cation and zwitterion, respectively, [22]. Using the emission spectra, and observed kinetic decays at these three wave- 

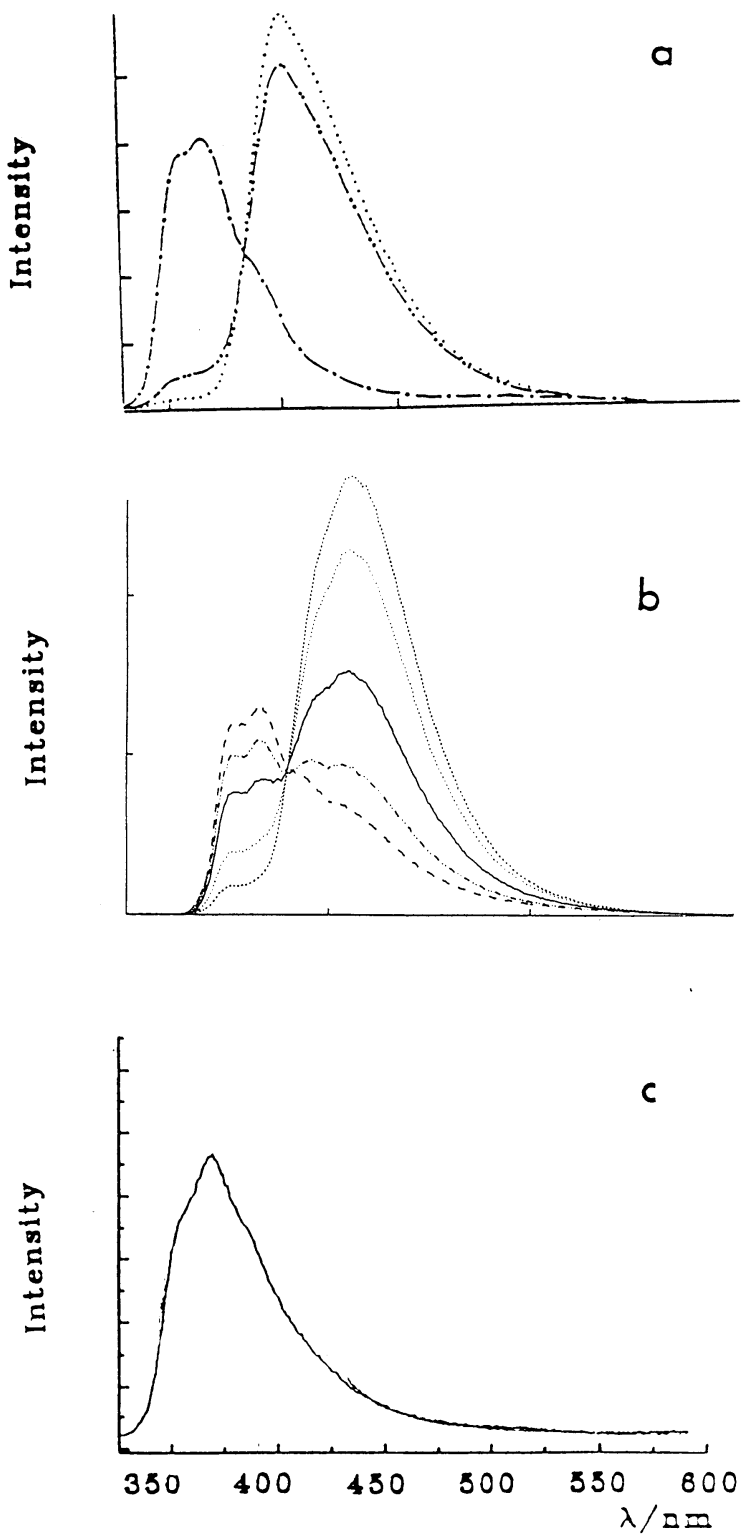

Fig. 4. Fluorescence spectra of harmine in microemulsions (a) water/AOT/cyclohexane microemulsions, $\omega_{0}=5$ at $\mathrm{pH} 10.3$ (. .), 12.0 (- . - ) and 12.8 (- . -); (b) water/AOT/cyclohexane microemulsions, $\omega_{0}=12.5$ at various $\mathrm{pH}$ values between 5.5 and 12.4 ; (c) water $/ \mathrm{AOT} / \mathrm{CCl} 4$ microemulsions at $\omega_{0}=5$.

lengths, analysis has been made in terms of four species, neutral in microemulsion droplets, neutral in cyclohexane, cation and zwitterion [22]. In these studies, all the four species were observed over the whole apparent $\mathrm{pH}$ range studied, show- ing that there must be partitioning in both ground and excited states between the aqueous domain and the bulk cyclohexane. The lifetime of the neutral form in cyclohexane in these microemulsions, decreases with increasing $\omega_{0}$, and from analysis of the data it was shown that this diffuses into the droplets with rates close to diffusion control [22].

If harmine is located predominantly at the amphiphile/water interface, the observation of cation at much higher apparent $\mathrm{pH}$ values than in water may be due, in part, to changes in its $\mathrm{p} K_{\mathrm{a}}$. However, this is unlikely to be the whole story, as although the ground and excited state $\mathrm{p} K_{\mathrm{a}}$ values differ by $5 \mathrm{pH}$ units in pure water, the changes in ground and excited state acid-base equilibria seen in microemulsions only appear to differ by $1-2$ $\mathrm{pH}$ units. It is difficult to see how an interface could affect these properties so dramatically. Under the unbuffered conditions used in this study the compartmentalisation of hydroxide ions between microemulsion droplets must also be important. Following the ideas initially advanced by Tachiya [39] and Infelta [40], and subsequently developed by Almgren [41], we have used a Poisson distribution and calculated the fraction of microemulsion droplets containing between 0 and 4 hydroxide ions [22]. These are illustrated in Fig. 5 , and give what, on first sight, is an unexpected result; up to fairly high apparent $\mathrm{pH}$ values the number of droplets containing hydroxide ions is very small. The previously reported buffering effect of microemulsions $[13,14]$ can thus be seen to result, at least in part, from the compartmentalisation effects of hydroxide ions between the $\mathrm{nm}$ sized water domains. Similar results have been presented for the partitioning of hydrogen ions $[42,43]$. Under these conditions, it is not clear that $\mathrm{pH}$ has any real thermodynamic or kinetic significance in microemulsions.

Both the structure and size of microemulsion droplets can be affected by the presence of a cosurfactant. This has consequences on the degree of compartmentalisation. Solutions of harmine in water $\left(\omega_{0}=5\right) / \mathrm{AOT}(0.1 \mathrm{M}) /$ cyclohexane were studied in the presence of various concentrations of 2-ethylhexanol. In both the absorption and fluorescence spectra, the contribution of the neu- 
tral form of harmine increased with increasing concentration of cosurfactant. Representative fluorescence spectra at apparent $\mathrm{pH} 11.37$ and different 2-ethylhexanol concentrations are shown in Fig. 6. These clearly indicate a decrease in the emission due to the cationic form at $403 \mathrm{~nm}$ on increasing cosurfactant concentration, and are in

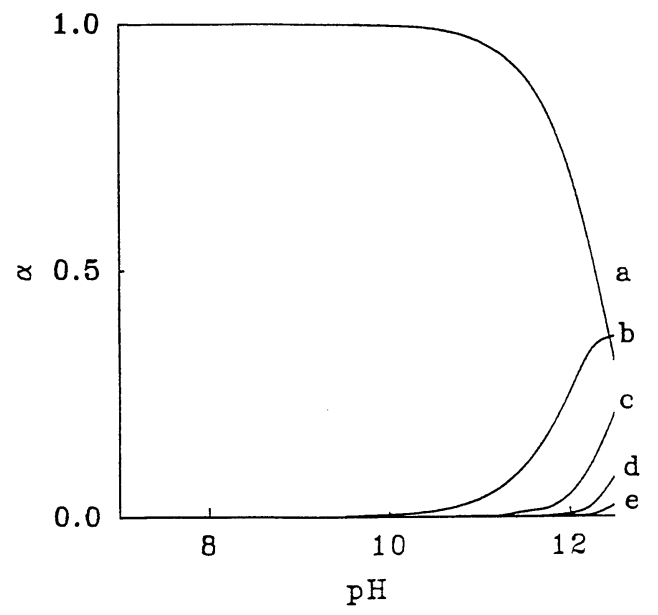

Fig. 5. Poisson distribution of number of hydroxide ions per microemulsion droplet as a function of $\mathrm{pH}$ for the system water $\left(\omega_{0}=12.5\right) / \operatorname{AOT}(0.1 \mathrm{M}) /$ cyclohexane for (a) 0 , (b) 1 , (c) 2, (d) 3, (e) 4 hydroxide ions per droplet. Reprinted with permission from A.P. Varela, M. da Graça Miguel, A.L. Maçanita, H.D. Burrows and R.S. Becker, J. Phys. Chem. (1995) (99) 16093. Copyright (1995) American Chemical Society.

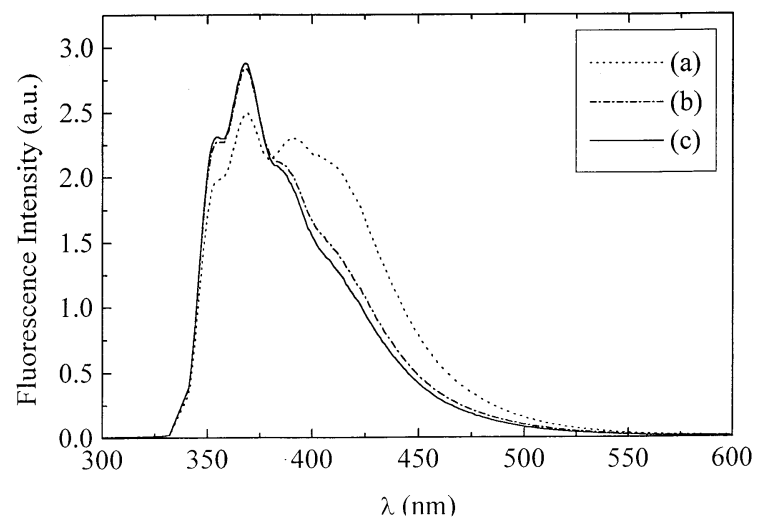

Fig. 6. Fluorescence spectra of harmine in water $\left(\omega_{0} 5\right) / \mathrm{AOT}$

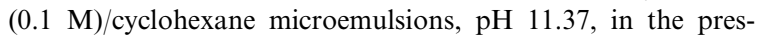
ence of 2-ethylhexanol (a) $0.2 \mathrm{M}$; (b) $0.4 \mathrm{M}$; (c) $0.6 \mathrm{M}$. agreement with the increasing size of the water droplets, and, consequently, the increasing of the probability that the same droplet will have both hydroxide ion and harmine.

Carbon tetrachloride is found to quench harmine fluorescence. Absorption and fluorescence spectra were run on harmine in $\mathrm{H}_{2} \mathrm{O}$ /AOT $(0.1 \mathrm{M}) / \mathrm{CCl}_{4}$ microemulsions, with $\omega_{0}=5$. A typical fluorescence spectrum is shown in Fig. 4(c), and again shows that emission comes just from cation in the water domain. The $\mathrm{pH}$ of the water pools was increased by adding aqueous ammonia, and under these conditions it was possible to see the fluorescence of the neutral form at $367 \mathrm{~nm}$. This indicates that some of the neutral harmine must be located at the interface, since neutral harmine has a low solubility in water, and the fluorescence of neutral harmine in $\mathrm{CCl}_{4}$ is quenched. However, it was not possible to get any quantitative information, as with time, marked changes were observed in the emission spectrum, and new bands appeared at longer wavelengths, possibly due to photodegradation [43]. Photodegradation of $\beta$-carbolines in chlorinated hydrocarbons has been reported earlier [44], and these results confirm that some fraction of the harmine must be in the organic solvent. Combination of this result with the observation of fluorescence from the neutral form of harmine at the interface is in agreement with the idea already presented [22] of a dynamic partitioning of harmine between the droplet and the organic solvent.

The behaviour of harmine was also studied in water/lecithin $(0.05 \mathrm{M})$ /cyclohexane microemulsions for $\omega_{0}$ between 12.5 and 17.5. This range was limited by the stability of these microemulsions. In both absorption and fluorescence spectra, the cationic form of harmine was observed up to higher apparent $\mathrm{pH}$ values than in pure water. For example, in Fig. 7 fluorescence spectra are shown for microemulsions at $\mathrm{pH} 11.75$ and $\omega_{0}$ 12.5 and 17.5, where emissions from both the cationic and neutral forms are observed. As with water/AOT/cyclohexane microemulsions, the relative contribution of the neutral form increases with $\omega_{0}$. Fluorescence decays of harmine at 350, 410 and $500 \mathrm{~nm}$ were obtained in these microe- 


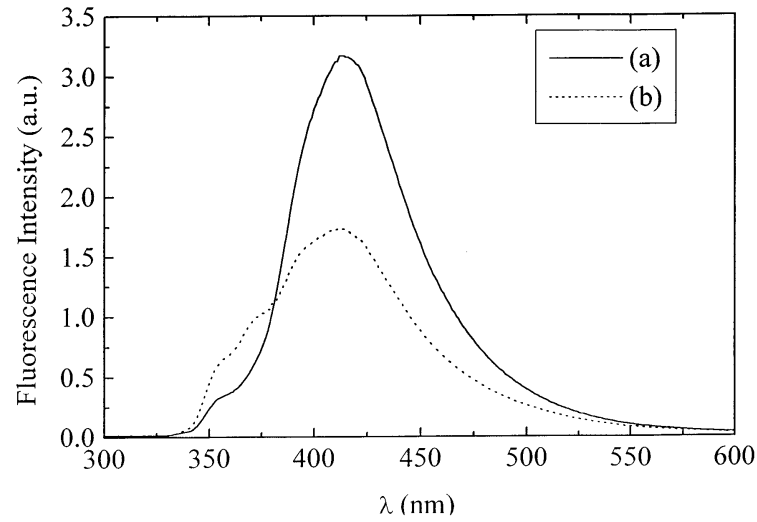

Fig. 7. Fluorescence spectra of harmine in water/lecithin $(0.05$ $\mathrm{M}) /$ cyclohexane microemulsions at $\mathrm{pH} 11.75$ for (a) $\omega_{0} 12.5$; (b) $\omega_{0} 17.5$.

mulsions at various $\mathrm{pH}$ values between 5.3 and 12.5. Again these were analysed in terms of four components. For the specific case of $\omega_{0} 17.5, \mathrm{pH}$ 11.92, the decay components were attributed to neutral in water pool $\left(\tau_{1}=0.67 \pm 0.11 \mathrm{~ns}\right)$, neutral in cyclohexane $\left(\tau_{2}=4.67 \pm 0.28 \mathrm{~ns}\right)$, cation $\left(\tau_{3}=\right.$ $6.67 \pm 1.17 \mathrm{~ns})$ and zwitterion $\left(\tau_{4}=18.5 \pm 1.5 \mathrm{~ns}\right)$. The zwitterion contribution was fairly small, and appeared to be markedly less than in water/AOT/ cyclohexane microemulsions. On decreasing the $\mathrm{pH}$ at constant $\omega_{0}$, the contribution of the cation relative to the neutral form increased, while the lifetime of the neutral form in both water pool and cyclohexane decreased. These decreases in $\tau_{1}$ and $\tau_{2}$ parallel the behaviour in water/AOT/cyclohexane microemulsions, and suggest that neutral excited harmine can diffuse from cyclohexane into the water pool, where it is quenched by reaction with protons and/or water. For constant $\mathrm{pH}$, the relative contribution of the neutral form decreased with decreasing $\omega_{0}$, in agreement with what is observed in the fluorescence spectra.

\subsection{Chromotropic acid}

Well-defined changes are observed in both absorption and fluorescence spectra on varying $\mathrm{pH}$ of aqueous solutions of chromotropic acid. Typical spectra are shown in Fig. 8. From these spectral changes, values of $\mathrm{p} K_{\mathrm{a}}=5.65$ and $\mathrm{p} K_{\mathrm{a}}^{*}=2.19$ were determined. The values for the ground state are in reasonable agreement with the literature data [45].

Carbon tetrachloride was found to quench the fluorescence of both the chromotropic acid and its conjugate base. Attempts to study chromotropic acid in water/AOT $/ \mathrm{CCl}_{4}$ microemulsions by fluorescence were unsuccessful due to phase separation. However, chromotropic acid was soluble in water/AOT $(0.1 \mathrm{M})$ /carbon tetrachloride-isooctane $(50 \%(\mathrm{v} / \mathrm{v}))$ up to $\omega_{0}=6$. A reasonably intense band around $430 \mathrm{~nm}$ was observed in the fluorescence spectra in this medium, and confirms that chromotropic acid is located predominantly inside the water domain.

Absorption and fluorescence spectra were run for chromotropic acid in water/AOT $(0.1 \mathrm{M}) /$ cyclohexane microemulsions at various $\mathrm{pH}$ values for $\omega_{0}$ between 2.5 and 40. Typical data are illustrated in Fig. 9. At the lowest $\mathrm{pH}$ value studied (2.5) for $\omega_{0}=2.5$, the major contribution to the absorption spectrum came from the conjugate base form. However, with increasing $\omega_{0}$, significant contributions were also observed from the acid. These results are consistent with the acid-base equilibria of chromotropic acid being dependent on the compartmentalisation of $\mathrm{H}^{+}$ between the water pools. At low $\omega_{0}$ values, there are few protons in each water pool, and equilibrium lies on the side of chromotropic acid conjugate base. As $\omega_{0}$ increases, more pools contain both protons and probe, and between $\omega_{0} 10$ and 40 it is possible to see equilibria between the acid and conjugate base forms over the apparent $\mathrm{pH}$ range $2-7$.

Fluorescence spectra were also recorded for chromotropic acid in water/AOT $(0.1 \mathrm{M})$ /cyclohexane microemulsions (Fig. 9). At the lowest $\omega_{0}$-value (2.5), the spectra appeared to show emission from both acid and conjugate base forms. However, this result contradicts what is observed in absorption spectra. A more probable explanation is that there is complexing between chromotropic acid and AOT head group, as has been suggested for related compounds [19]. Above $\omega_{0}=10$, the dominant emission is at around 430 $\mathrm{nm}$, and is attributed to the conjugate base. More detailed studies on this system are in progress and will be reported in due course. 

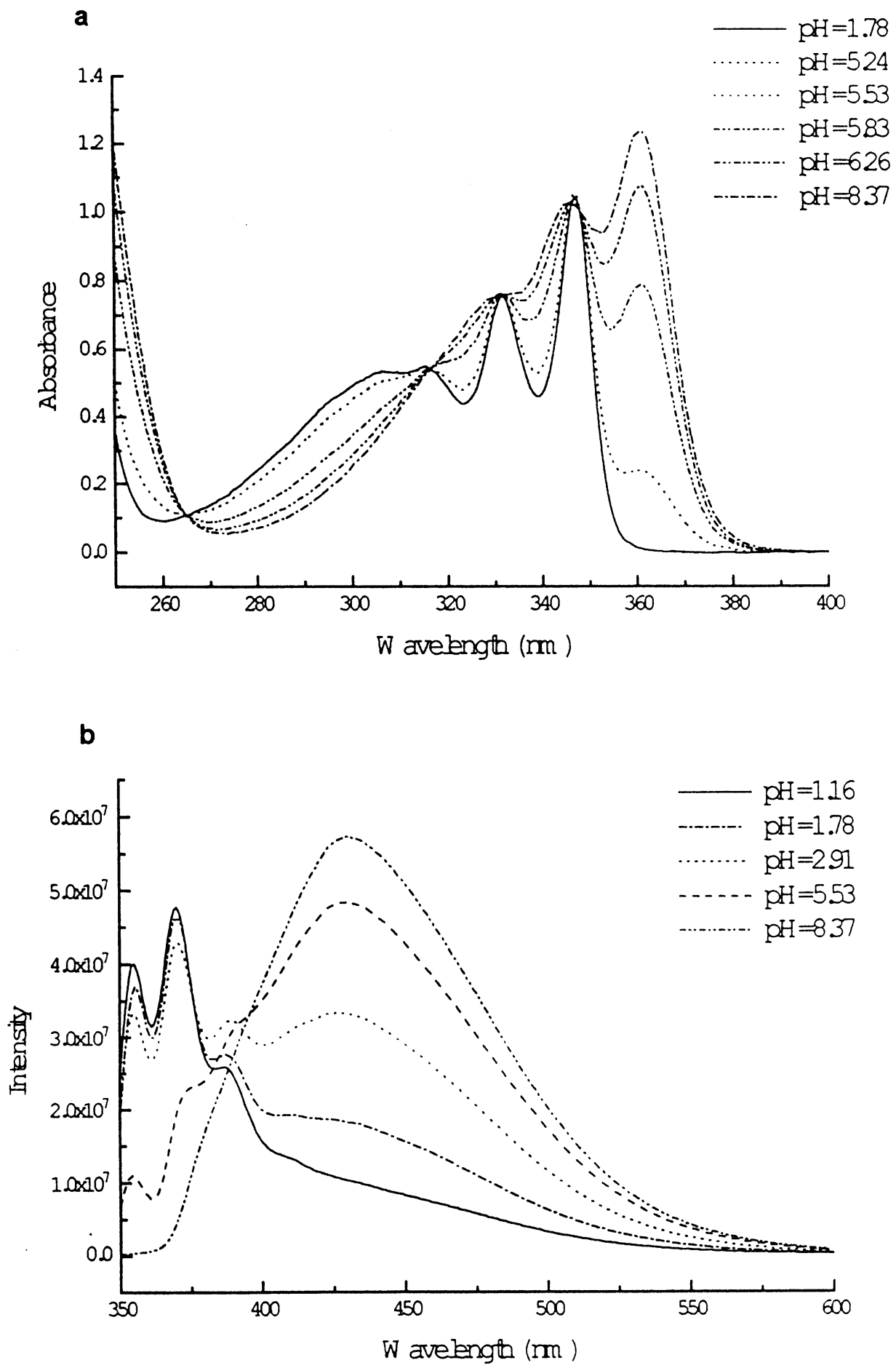

Fig. 8. (a) Absorption and (b) fluorescence spectra of aqueous solutions of chromotropic acid at various $\mathrm{pH}$ values. 


\subsection{2-Naphthol}

The behaviour of 2-naphthol in $\mathrm{H}_{2} \mathrm{O} / \mathrm{AOT} /$ heptane microemulsions has been reported earlier [19]. From differences between absorption or fluorescence spectra in this medium and pure heptane it was suggested that the solute is located predominantly at the interface in the microemulsion. Surprisingly this molecule did not undergo deprotonation in its excited state, even though its low $\mathrm{p} K_{\mathrm{a}}^{*}$ value (2.8 [46]) would favour this process. This was interpreted in terms of complexing

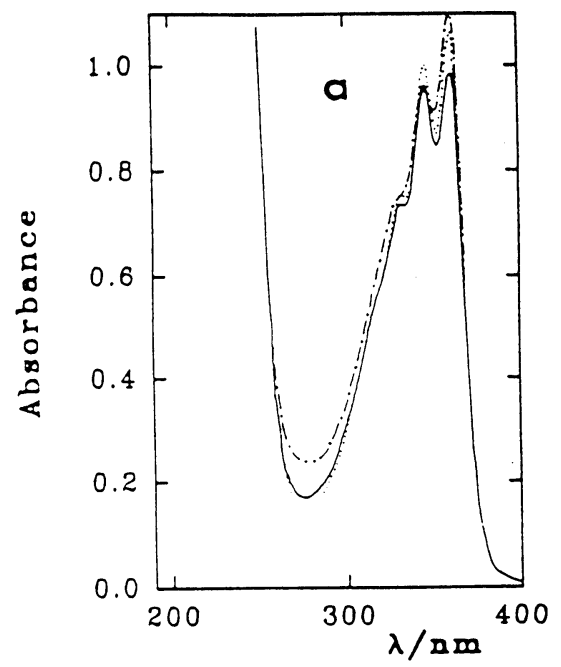

the naphthol to the AOT sulfonate headgroup [19]. However, it is difficult to see what the driving force is for such an interaction.

We have studied the behaviour of 2-naphthol in water/AOT $(0.1 \mathrm{M}) / \mathrm{CCl}_{4}$ at various $\mathrm{pH}$ values with $\omega_{0} 5-10$ using both absorption and fluorescence. Studies in ethanol solution show that carbon tetrachloride quenches both the neutral and ionic forms of 2-naphthol with rates close to diffusion control [43], so that any fluorescence can only come from the probe in the water pool or interface. Up to apparent $\mathrm{pH} 13$ there is no sign

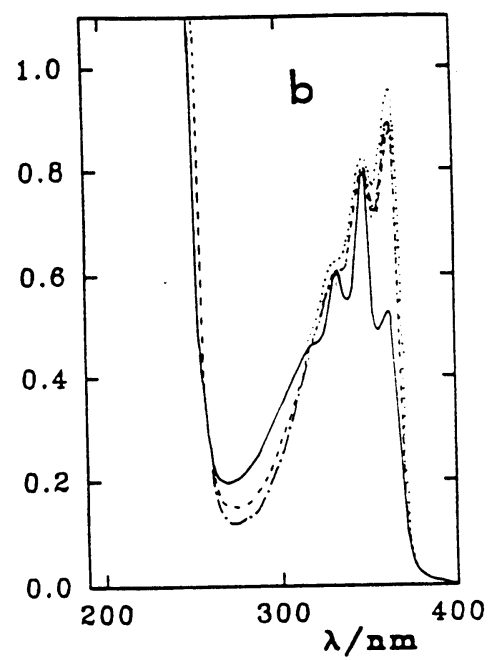

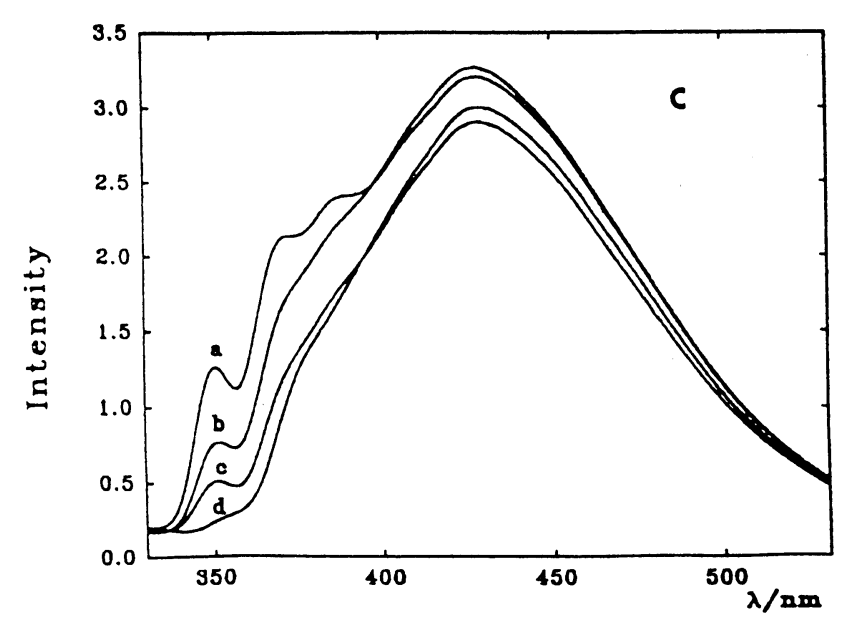

Fig. 9. Absorption spectra of aqueous solutions of chromotropic acid in water/AOT/cyclohexane microemulsions at various $\mathrm{pH}$ values (2.1-7.0) at $\omega_{0}$ (a) 5; (b) 15; (c) fluorescence spectra of aqueous solutions of chromotropic acid in water/AOT/cyclohexane microemulsions at $\omega_{0}=10$ at various $\mathrm{pH}$ values between 2.0 and 6.1 . 
a
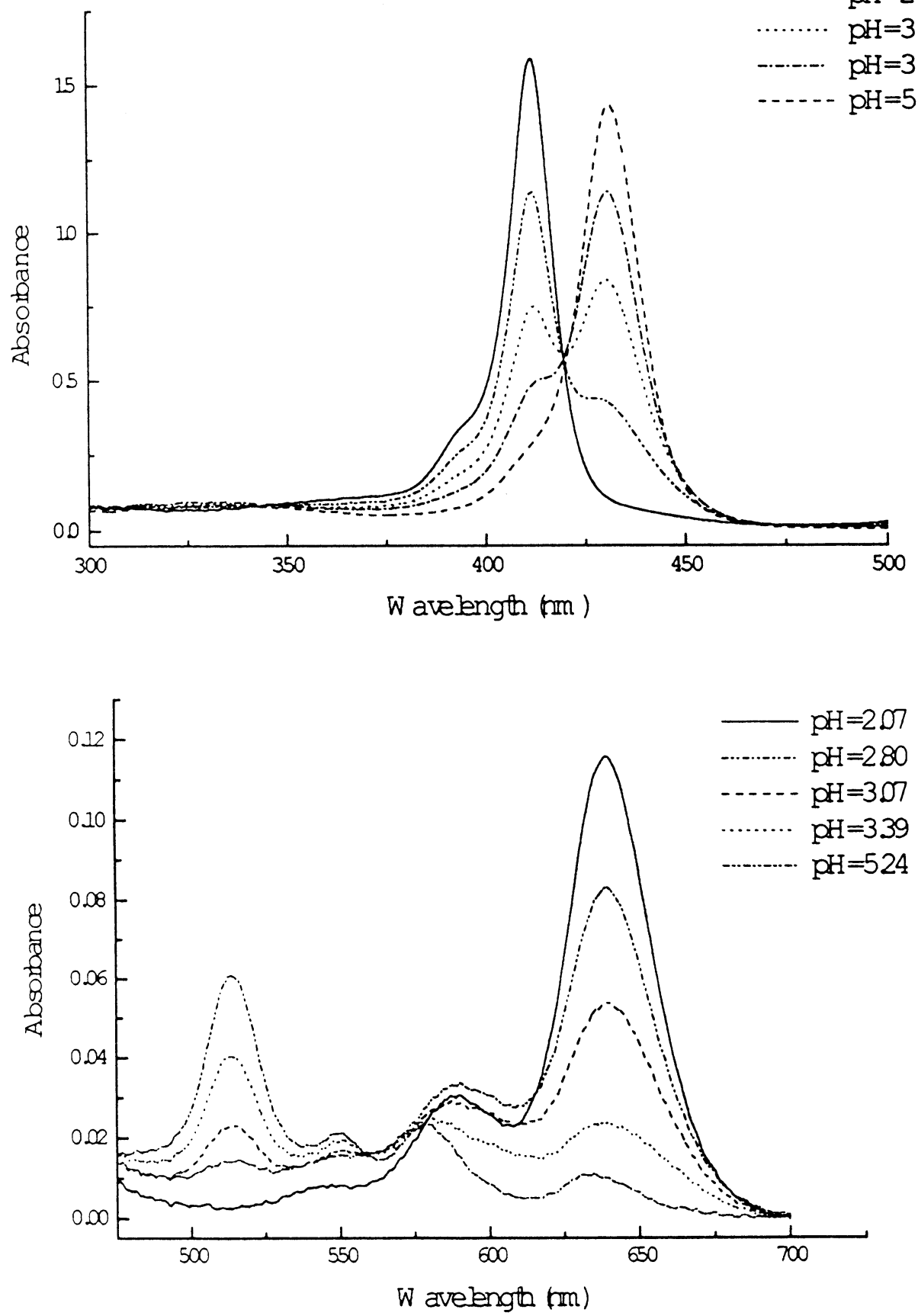

Fig. 10. (a) Absorption spectra of Soret and Q band region of aqueous solutions of TTMP in water at various pH values; (b) spectrophotometric titration curves for absorption changes at $411.8 \mathrm{~nm}$ (triangles) and $430.5 \mathrm{~nm}$ (squares and circles) for aqueous solutions of TTMP. 


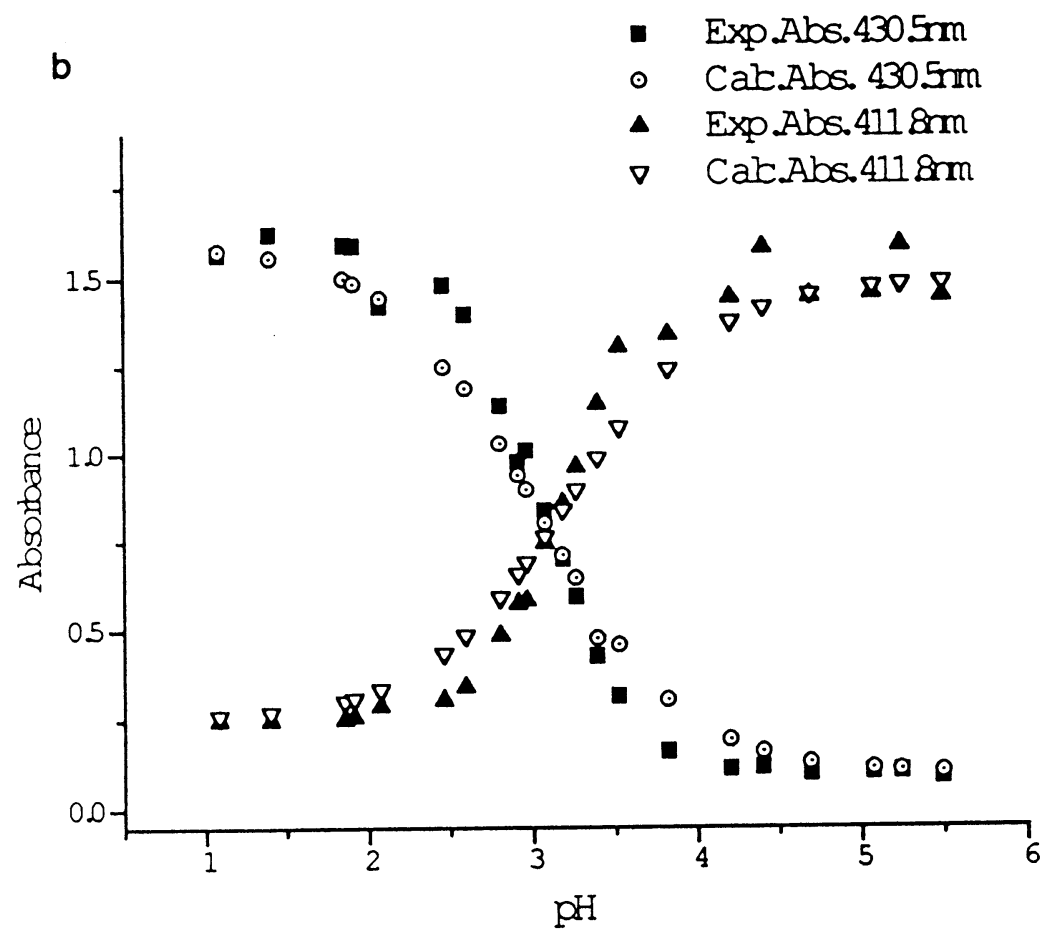

Fig. 10. (Continued)

of any fluorescence in these microemulsions, showing that the excited 2-naphthol is completely quenched. It must either be in the organic phase, or have ready access to it during its lifetime. If, as suggested [19], it is complexed by the AOT then the complex must be nonfluorescent. However, sulfonates are not known to be good quenchers of fluorescence of aromatic compounds. We feel that the most plausible explanation for our observations is that most of the 2-naphthol is in the carbon tetrachloride. At apparent $\mathrm{pH} 13.15, \omega_{0}=$ 10 , a very weak fluorescence around $420 \mathrm{~nm}$ is observed. This is attributed to the 2-naphtholate anion, and must arise from the small percentage of water pools, which have both probe and hydroxide ions.

\subsection{TTMP}

Absorption spectral studies on aqueous solutions of TTMP show spectral changes in the $\mathrm{pH}$ range 2-5. Spectral changes in the $350-500 \mathrm{~nm}$ region (Soret band), together with a titration curve are shown in Fig. 10. From this, a value of $\mathrm{p} K_{\mathrm{a}}=3.11$ was obtained. Changes are also observed in the 500-700 $\mathrm{nm}$ region ( $\mathrm{Q}$ band), and the change in spectrum from four to two bands consistent with a change in symmetry [47] due the double proton transfer reaction shown in Fig. 2. Changes in fluorescence spectra are also observed over this $\mathrm{pH}$ range, and are also shown in Fig. 11. From these a value of $\mathrm{p} K_{\mathrm{a}}^{*}=2.93$ was obtained. Solubility measurements and partitioning studies of TTMP between water and carbon tetrachloride show that it is completely insoluble in $\mathrm{CCl}_{4}$, and partitions both above and below the $\mathrm{p} K_{\mathrm{a}}$ to the aqueous phase.

Preliminary studies have been made of the porphyrin in water/AOT/ $\mathrm{CCl}_{4}$ microemulsions up to $\omega_{0}=6$ [43]. These show that TTMP only exists as the free base in these systems. However, slight differences are observed in both absorption and fluorescence spectra, compared with pure water, and it is probable that this positively charged compound is located at the AOT-water interface. It is worth noting that the molecule has a discotic 
shape, and its size is comparable to the radius of the water pool. From X-ray diffraction (XRD) measurements, the diameter of 5,10,15,20 tetrakis(phenyl)-21H,23H-porphine diacid is about 1.5 $\mathrm{nm}$ [48], while if we calculate the diameter of a water droplet for $\omega_{0}=6$ using data for water/ AOT/decane microemulsions [49], we get a value $1.44 \mathrm{~nm}$. Under these conditions, it is very probable that we are in the suggested situation [4] where the aggregates are formed round the porphyrin, and are stabilised by electrostatic interactions.

\section{Discussion}

It has long been known [13-15] that when aqueous solutions of a certain $\mathrm{pH}$ are added to produce $\mathrm{w} / \mathrm{o}$ microemulsions, the apparent $\mathrm{pH}$ of the resultant water domains is different from the value of the original aqueous solution. In some cases, buffers are added to try to avoid this problem. However, the microemulsion properties of water/surfactant/oil systems may be altered by the presence of buffer, and for many applications it is desirable to prepare buffer-free solutions.
The main reasons proposed for this effect of microemulsion can be divided into effects of microemulsion structure and interfaces on $\mathrm{p} K$ values or on the autoprotolysis of water, possibilities of $\mathrm{pH}$ gradients in microemulsions and distribution effects of solutes, hydrogen and hydroxide ions. In this study, we have looked at the behaviour of four probes, which can be located in the water microdomain, interface or oil, depending on ionisation. In all cases the apparent $\mathrm{pH}$ of solutions is found to differ from that of the added solution. Fluorescence studies using harmine, which shows different acid-base equilibria in ground and excited states, suggest that the dominant effect is not a change in $\mathrm{p} K_{\mathrm{a}}$ when the probe is at the interface. Instead it is suggested that compartmentalisation of hydroxide and solute ions between the water pools is important. Similarly, it is shown that at $\mathrm{pH}<7$, compartmentalisation of hydrogen ions is also important. In these circumstances, attempts to define 'apparent $\mathrm{pH}$ scales' are of limited use. However, the buffering effect of microemulsions, caused by this compartmentalisation, does have one very important practical consequence. Under these conditions, the majority

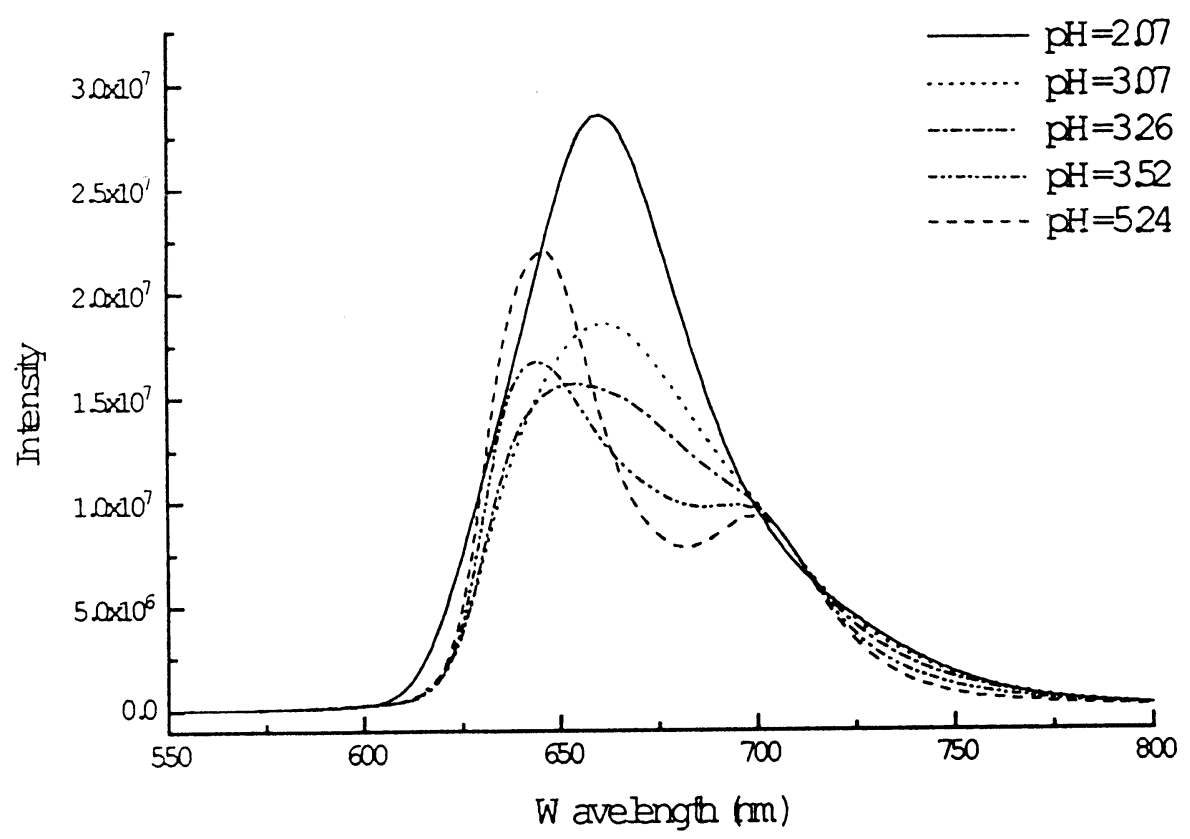

Fig. 11. Fluorescence spectra for aqueous solutions of TTMP at various $\mathrm{pH}$ values. 
of water pools will be close to neutrality so that for any enzymic or other process which would normally occur in aqueous solution around $\mathrm{pH} 7$, it is not necessary to add any extra component if the reaction is carried out in $\mathrm{w} / \mathrm{o}$ microemulsion droplets.

Fluorescence lifetime measurements on harmine in water/AOT/cyclohexane microemulsions also show another important effect in these systems; that of diffusion of solutes between organic solvent and the water microdomains. This process can be rapid, with rates that depend upon diffusion control.

\section{Acknowledgements}

We are greatly indebted to Professor A.L. Maçanita (I.T.Q.B.) for access to the time-correlated single-photon-counting equipment, and to him and to Professor R.S. Becker for valuable discussions on the photophysics of $\beta$-carbolines. Financial support from PRAXIS XXI (project $2 / 2.1 /$ QUI/411/94) and JNICT is gratefully acknowledged. This paper was prepared when $\mathrm{M}$. da Graça Miguel was visiting professor at Department of Physical Chemistry 1, Lund University. The support from Lund University is also acknowledged.

\section{References}

[1] H.F. Eicke, Top. Curr. Chem. 87 (1980) 85.

[2] S.E. Friberg, P. Bothorel (Eds.), Microemulsions: Structure and Dynamics, CRC Press, Boca Raton, FL, 1987.

[3] A. Author, in: S.E. Bourrel, R.S. Schecter (Eds.), Microemulsions and Related Systems: Formulations, Solvency and Physical Properties, Marcel Dekker, New York, 1988.

[4] P.L. Luisi, M. Giomini, M.P. Pileni, B.H. Robinson, Biochim. Biophys. Acta 947 (1988) 209.

[5] Y. Chevalier, T. Zemb, Rep. Prog. Phys. 53 (1990) 279.

[6] M. Kahlweit, R. Lipowsky, Ber. Bunsenges Phys. Chem. 100 (1996) 181-393.

[7] B. Jönsson, B. Lindman, K. Holmberg, B. Kronberg, Surfactants and Polymers in Aqueous Solutions, Wiley, Chichester, 1998.

[8] J.H. Fendler, Acc. Chem. Res. 9 (1976) 153.

[9] P.L. Luisi, Angew Chem. Int. Ed. Engl. 24 (1985) 439.
[10] A. Author, in: M.P. Pileni (Ed.), Structure and Reactivity in Reverse Micelles, Elsevier, Amsterdam, 1989.

[11] L. Motte, M.P. Pileni, J. Phys. Chem. B 102 (1998) 4104.

[12] K.M. Lusvardi, K.-V. Schubert, E.W. Kaler, Ber. Bunsenges Phys. Chem. 100 (1996) 373.

[13] M. Miyoshi, G. Tomita, Z. Naturforsch. 35b (1980) 736.

[14] V.V. Vanag, I. Hanazaki, J. Phys. Chem. 100 (1996) 10609.

[15] F.M. Menger, K. Yamada, J. Am. Chem. Soc. 101 (1979) 6731.

[16] H. Fujii, T. Kawai, H. Nishikawa, Bull. Chem. Soc. Jpn. 52 (1979) 2051.

[17] O.A. El Seoud, A.M. Chinelatto, J. Colloid Interface Sci. 95 (1983) 163.

[18] R.E. Smith, P.L. Luisi, Helv. Chim. Acta. 63 (1980) 2302.

[19] E. Bardez, E. Monnier, B. Valeur, J. Phys. Chem. 89 (1985) 5031.

[20] C.A. Boicelli, F. Conti, M. Giomini, A.M. Giuliani, Spectrochim. Acta Part A 38A (1982) 299.

[21] A. Dias, A.P. Varela, M. da Graça Miguel, A.L. Maçanita, R.S. Becker, J. Phys. Chem. 96 (1992) 10290.

[22] A.P. Varela, M. da Graça Miguel, A.L. Maçanita, H.D. Burrows, R.S. Becker, J. Phys. Chem. 99 (1995) 16093.

[23] A. Dias, A.P. Varela, M. da Graça Miguel, R.S. Becker, H.D. Burrows, A.L. Maçanita, J. Phys. Chem. 100 (1996) 17970.

[24] C. Sen, N. Ueno, B. Chakrabarti, Photochem. Photobiol. 55 (1992) 753.

[25] F.T. Vert, I.Z. Sanchez, A.O. Torrent, J. Photochem. 23 (1983) 355.

[26] P.A. Winsor, Trans.Faraday Soc. 44 (1948) 390.

[27] J. Sunamoto, T. Hamada, T. Seto, S. Yamamoto, Bull. Chem. Soc. Jpn. 53 (1980) 583.

[28] H. MacDonald, B. Bedwell, E. Gulari, Langmuir 2 (1986) 704.

[29] G. Onori, A. Santucci, J. Colloid Interface Sci. 150 (1992) 195.

[30] G. Onori, A. Santucci, J. Phys. Chem. 97 (1993) 5430.

[31] K. Iwata, H. Hamaguchi, J. Mol. Struct. 413/414 (1997) 101.

[32] A.S. Sadaghiani, A. Noori, A. Khan, J. Surf. Sci. Technol. 7 (1991) 163.

[33] G. Cavallaro, G. La Manna, V. Turco Liveri, F. Aliotta, M.E. Fontanella, J. Colloid Interface Sci. 176 (1995) 281.

[34] P. Schurtenberger, Q. Peng, M.E. Leser, P.-L. Luisi, J. Colloid Interface Sci. 156 (1993) 43.

[35] P. Schurtenberger, R. Scartazzini, L.J. Magid, M.E. Leser, P.-L. Luisi, J. Phys. Chem. 94 (1990) 3695.

[36] S.O. Amire, H.D. Burrows, J. Chem. Soc., Faraday Trans. 178 (1982) 2033.

[37] H.D. Burrows, M. da Graça Miguel, A.P. Varela, R.S. Becker, Thermochim. Acta 279 (1996) 77.

[38] H.D. Burrows, M. da Graça Miguel, G. Miguel, A.P. Varela, R.S. Becker, Thermochim. Acta 279 (1996) 77.

[39] M. Tachiya, in: G.R. Freeman (Ed.), Kinetics of Nonhomogeneous Processes, Wiley, New York, 1987, pp. 575650 . 
[40] P.P. Infelta, Chem. Phys. Lett. 61 (1979) 88.

[41] R. Jóhannsson, M. Almgren, Langmuir 9 (1993) 2879.

[42] A. Lopes, Ph.D. Thesis, I.T.Q.B., Universidade Nova de Lisboa, 1997.

[43] M.A.R. Escaroupa Pereira, M.Sc. Thesis, Universidade de Coimbra, 1998.

[44] M.C. Biondic, R. Erra-Balsells, J. Photochem. Photobiol. A 77 (1994) 149.
[45] D.D. Perrin, IUPAC Chemical Data Series No.22. Stability Constants of Metal Ion Complexes Part B, Organic Ligands, Pergamon, Oxford, 1979, p. 738.

[46] T. Forster, Z. Electrochem. 54 (1950) 531.

[47] M. Gouterman, J. Mol. Spectrosc. 6 (1961) 138.

[48] A. Stone, E.B. Fleischer, J. Am. Chem.Soc. 90 (1968) 2735.

[49] C. Izquierdo, M.L. Moyá, J.L. Usero, J. Casado, Monatsh.Chem. 123 (1992) 383. 